\title{
SESIÓN NECROLÓGICA EN MEMORIA DEL PROF. JUAN JIMÉNEZ COLLADO
}

Pedro Guillén García

Académico de Número de la Real Academia Nacional de Medicina de España - Traumatología y Cirugía Ortopédica

Excmo. Sr. Presidente de la RANME.

Excmos. e Ilmos. Señoras y Señores académicos.

Amigos y alumnos que nos acompañan en esta solemne Sesión Académica Necrológica.

Escribo esta necrología tuya, querido amigo y maestro D. Juan, no pasado un año de tu muerte y el recuerdo fúnebre se convierte en reconocimiento de grandezas y ejemplaridad gozosas y en muestra de gratitud por la docencia recibida.

\section{A MODO DE JUSTIFICACIÓN}

Durante esta pandemia tan ruidosa del coronavirus recibí una llamada del Presidente Prof. Joaquín Poch encargándome, según acuerdo de la Junta Directiva de la Academia, que escribiera la sesión necrológica del Prof. Juan Jiménez Collado por ser yo el académico más cercano y sin dudar le contesté que sí y que constituía un gran honor para mí.

Gracias, Sr. Presidente, por haberme otorgado el honor de hacer la necrológica, o elogio u honra fúnebre del Prof. Juan Jiménez Collado, insigne miembro de nuestra corporación durante veintisiete años. Siempre he escrito mis publicaciones por la noche ya que el día lo ocupaba por entero a los enfermos y ahora emborrono estas cuartillas, durante la pandemia del Covid-19, sin la ayuda de las estrellas que guiaban mi bolígrafo para encontrar la palabra justa que exprese lo que mi pensamiento encierra.

Y aquí y ahora me presento ante ustedes, Excmos. Académicos para cumplir el encargo de la Academia y glosar de la mejor manera que sé su perfil humano, universitario y científico de nuestro excompañero de corporación.

Recordar hoy la persona y la gran obra docente del Profesor Juan Jiménez Collado insigne miembro de nuestra Corporación por 27 años, es un gran honor que me ha otorgado la Academia y que agradezco y ruego me perdonen si al aceptar tan honroso encargo me refiera con frecuencia a mi relación personal con nuestro recordado compañero y a los quehaceres, ilusiones y afanes que compartimos los dos.
La sesión necrológica es un acto Académico para recordar y honrar al compañero y en donde también se exponen sus datos personales y sobre todo sus grandes logros alcanzados en el ejercicio de su profesión y con especial énfasis en su herencia docente e investigadora, así como su gran contribución a la Academia durante veintisiete años y acabar consolando a familiares y amigos.

En los últimos años, cada día a mi llamada telefónica interesándome por su salud y la de su mujer, fallecida tres días antes que D. Juan, siempre me contestaba igual, "vivo, Pedro, vivo" y $i^{\mathrm{D}}$ Maru cómo está?, "con dolores, Pedro, con dolores".

Redactaba D. Juan la contestación a mi discurso de entrada a la Academia, que retocó y cambió muchas veces y él que tenía mente brillante y excelente letra y manejo del dibujo, cariñosamente culpaba al papel, al bolígrafo y siempre a que no veía pese a tener una decena de gafas.

Sobre el mes de octubre pasado, tras escribir mi laudatio, excelente documento, respondió a mi admiración diciéndome "Pedro, lo que me falta es vida, movimiento, no cabeza”. El Prof. F. González de Posada fue decisivo en la elaboración del Laudatio, que además leyó. Muy agradecido querido Prof. F. González de Posada.

Así fue, se le dobló la columna, perdió capacidad de movimiento, su voz era un susurro y su mirada poco precisa, parecía venir del otro lado del misterio y aun así se interesaba por la actualidad de nuestro país y cómo iba la investigación sobre el envejecimiento así como por las incidencias de la vida académica.

D. Juan siempre enseñaba hasta en los más sencillos detalles y su grandeza espiritual de maestro se agigantaba cuando me decía "Pedro, soy y he sido muy exigente conmigo y con mis colaborares en la Universidad de Murcia, en la Universidad de Córdoba y en la Universidad Complutense de Madrid y si pudiera volver, haría menos exigente mi trabajo".

Para confeccionar esta nota necrológica de D. Juan me he servido del Curriculum Vitae que entregó en la RANME cuando ingresó en 1993, de la información solicitada a los profesores y alumnos en Murcia

\section{Autor para la correspondencia}


(Prof. P. Martínez) y en Madrid (Prof. J. Sobrado, F. de la Gala, J. Rodríguez) y sobre todo en los míos propios tras más de 50 años de convivencia fraternal. También me he alimentado para confeccionar esta necrológica del discurso de contestación que hizo el Prof. H. Durán Sacristán al ingreso en nuestra Academia del Prof. Juan Jiménez Collado.

Hoy D. Juan vives y vivirás mucho en tu obra anatómica y tus estudios sobre embriones representa uno de los más grandes legados de la embriología en España.

Sres. Académicos, hemos perdido al claro varón, al investigador exigente, al maestro de trabajo pulcro y detallista que sigue viviendo en su obra anatómica ejemplar de Profesor brillante ante el encerado pero el recuerdo de una vida así no mitiga el dolor de haber perdido al gran maestro de la disección en el cadáver y del encerado. En sus clases de anatomía a los alumnos dibujaba en el encerado con tizas de distintos colores y cuando el conserje iba a borrar se oía un murmullo negativo de los alumnos para tener tiempo de copiarlo. Cuando dibujaba "retrataba su pensamiento anatómico"

Enérgico, perfil yo diría árabe, mirada frontal, andar resuelto, palabra a más y precipitada por su torrente de conocimientos.

Puedo asegurar, porque se sabe, la profunda huella anatómica que ha dejado el Prof. Juan Jiménez Collado a su paso por la universidad española, primero en Murcia, luego en Córdoba y finalmente en la UCM.

Mi larga vivencia médica y personal con D. Juan, no es fácil comprimir en unos pocos minutos pero como primer pensamiento vaya mi gratitud por la herencia recibida, por tu ejemplaridad estimulante y por tu longevidad fructífera.

La amistad la cuidó y cultivó en extremo y con ella fue siempre leal, muy exigente y sincero, pues entendía muy bien que la vida sin amistad es inútil, como ya lo refería el proverbio latino "sensa amiticia vitans essen nulan"

Tampoco, ustedes Sres. Académicos, ni yo mismo, al hacer la necrología del Prof. Juan Jiménez Collado, pueden exigirme total objetividad en el relato de su vida como profesor de Anatomía y Embriología Humana, acaso solo la observarán en los datos, pues son los que son, que yo por cariño y justeza los adorne.

Investigó con gran ahínco en embriología y anatomía y ese quehacer lo inculcó a los componentes de su cátedra y llevaba al máximo el lema que "la universidad no investiga porque es buena, es buena porque investiga" y además enhebró la labor docente e investigadora porque entendía que debían potenciarse entre sí.

Disfrutaba en la sala de disección mostrando los detalles anatómicos y se plantaba bien y cómodo ante el cadáver y su disección con instrumentos o con el dedo era una continua enseñanza y si la técnica era difícil comentaba "para el anatómico y cirujano la excesiva prisa es pasión de necios". No presumas de una técnica quirúrgica o andadura o emprendimiento, hazlo al regreso, al terminar.

Su muerte nos ha privado de su presencia, pero siempre tendremos sus enseñanzas.

Preparaba con gran detenimiento sus clases a los alumnos porque sabía que en su profesión, vales lo que vas a enseñar mañana.

Fue D. Juan y Dña. Maru, un matrimonio feliz, sin hijos, vivieron la vida intensamente hasta que la enfermedad de ella en los últimos veinte años dejó al feliz matrimonio recluido en casa, y es que la vida se pierde cuando dejas de ser feliz, no cuando dejas de respirar.

Yo tuve la suerte de caminar mucho a su lado, en la medicina, en la anatomía, en la vida y con ello alcancé lo que estaba cercano y también lo muy lejano.

Era un batallador incesante, pero al servicio de la eficacia como rasgos esenciales de su personalidad. Lo descubrí en sus cristales o preparaciones histológicas, iluminados en el microscopio o a trasluz o con el visor de diapositivas y siempre llenos de estructuras humanas que describía con enorme justeza y entusiasmo, y con amor a la obra bien hecha pues desechaba cualquier preparación si tenía defectos de fijación, ¡ah! Y siempre con su igual en latín, como plus de conocimiento. Decía dibujando en el encerado con tizas de colores, "esta estructura corresponde al musculus gastronemius, caput laterale, y ésta al caput mediale y aquí vemos el ligamentum cruciatum anterius y el posterius"

\section{DATOS BIOGRÁFICOS DEL PROF. JUAN JIMÉNEZ COLLADO}

Nace el 30 de agosto de 1932 en San Roque, Cádiz, padre militar, madre ama de casa, hijo único. Estudia Bachillerato en Melilla y en Cádiz capital completa los estudios secundarios.

Estudia la carrera de medicina en la facultad de medicina de Cádiz, 1950 a 1956 con premio extraordinario de licenciatura.

En 1956 obtiene, por oposición la plaza de médico interno de Anatomía Humana Descriptiva y Topográfica y también la de médico interno por oposición de Patología Quirúrgica, ambas en la facultad de Medicina de Cádiz.

Doctor en Medicina y Cirugía en 1958 con premio extraordinario de doctorado en la Universidad de Sevilla.

D. Juan siempre nos recordaba que ejerció de médico en este caso de cirujano, en Cádiz con el Prof. Orts Llorca. Este ensamblaje anatómico y cirujano 
nos parece un excelente tándem. La anatomía y la traumatología se conjugan mutuamente, pues solo se fractura o lesiona "lo anatómico", "la estructura anatómica", que es tanto como decir que "todas las fracturas son la FRACTURA".

Obtiene por oposición la plaza de Prof. Adjunto de patología quirúrgica de la universidad de Cádiz en 1958.

También logra por oposición la plaza de Prof. Adjunto de Anatomía Humana de la Universidad de Cádiz en 1959.

En 1962 gana por oposición la plaza de Prof. Adjunto de Anatomía Humana, Topográfica y Técnicas Anatómicas de la Facultad de Medicina de la UCM, lo que va a suponer dedicarse sólo a la Anatomía.

En la Universidad Complutense de Madrid (UCM), la ayuda del gran maestro en Anatomía y en Embriología, Profesor F. Orts Llorca fue decisivo en su formación, aunque D. Juan siempre decía que su primer maestro fue el Prof. A. López Rodríguez en Cádiz.

El Prof. Juan Jiménez Collado, completó su formación con otros maestros extranjeros, Prof. Giroud en París (1961); El Prof. Tuachmang-Dupleis en París (1961); el Prof. Winckler en Lausanne (1965); el Prof. H. Galera en Ginebra (1968); El Prof. J. Salmon en Marsella (1969) y el Prof. Robertson en Menphis, Tennesse, USA (1971)

Catedrático contratado de Embriología y Anatomía de la facultad de Medicina de la Universidad de Murcia 1970.

Catedrático por oposición de Anatomía Humana Descriptiva y Topográfica con sus Técnicas de la Facultad de Medicina de la Universidad de Murcia 1971.

Catedrático en virtud de concurso/traslado de Anatomía Humana Descriptiva y Topográfica con sus técnicas de la Facultad de Medicina de Córdoba. Universidad de Córdoba 1975

Catedrático en virtud de concurso-traslado de Anatomía Humana Descriptiva y Topográfica con sus Técnicas de la Facultad de Medicina UCM 1977, donde se jubiló y pasó a Prof. Emérito.

\section{PREMIOS, BECAS, AYUDAS Y DIPLOMAS}

Premio fin de carrera, facultad Medicina Cádiz 1956. Diplomado por oposición en "Técnicas Sistema Nervioso y en Biología” 1956. También de la Escuela Nacional tórax del Ministerio de Sanidad y de la sanidad nacional 1959.

Ayuda investigación para el desarrollo de los miembros del Ministerio de Sanidad 1962-63 y ayuda de investigación sobre "injertos heterotópicos de esbozos de miembro" del Ministerio de Educación 1964.
Becas de investigación, "morfogénesis palatina" de UCM 1964; Beca Fundación F. Rostand "Laboratorio de Embriología” Facultad de Medicina París 1967; Beca Fundación W. Ford, "laboratorio de Anatomía", Facultad Medicina Lausanne 1969 y beca fundación Mapfre, "Patrón vascular de la rodilla" 1968.

Grant o beca o ayudas sobre "Heteroinjertos heterotópicos de esbozos presuntivos de miembros" comisión asesora de Presidencia de Gobierno sobre "Análisis experimental de la regulación cardiaca" 1980-81-82"; Grant sobre "Análisis experimental de los mecanismos reguladores de los miembros", New York, 1986; Grant del Instituto Federico Mattiazo sobre "Morfogénesis apendicular" Roma 1989 y Grant de la congenital Spinal Disease Fundation sobre "Neuroschisis and human embryonic and development" New York, 1990.

Título de "Especialista en cirugía General” Ministerio Educación y Ciencia 1980; Título de Especialista en Medicina del Trabajo Ministerio Educación y Ciencia 1984.

\section{CARGOS ADMINISTRATIVOS Y NOMBRA- MIENTOS}

Académico correspondiente de la Real Academia de Cádiz 1966; Académico correspondiente de la Real Academia de Murcia, 1973; Académico de número de la Real Academia de Medicina Murcia 1973; Secretario de la Facultad de medicina de la Universidad de Murcia 1970 y Director de las Escuelas ATS Facultad de medicina de la Universidad de Murcia 1970-1977.

En Córdoba, Decano de la Facultad de medicina de la Universidad de Córdoba 1975; Decano de la Beneficiencia de Córdoba 1975; Director del Hospital Clínico Universitario de la Facultad de medicina de la Universidad de Córdoba 1975 y director de la escuela ATS de la Facultad de Medicina de la Universidad de Córdoba 1977.

En Madrid, Universidad Complutense de Madrid (UCM)

- $\quad$ Vicedecano de investigación. 1977 a 1987

- Director Escuela Universitaria de Enfermería 1979-1982

- Presidente Comisión Investigación 1979-1987

- Director Departamento Anatomía de 1985-1989

- Director Fundador Instituto de Embriología de UCM 1987-2006

- Director del Instituto de ciencia morfofuncionales, 1989-2006

Miembro del equipo de investigación Grant Fundación Juan March sobre "Análisis experimental de la regulación cardiaca, UCM" 1964; miembro equipo investigación Grant Aid crippled children. UCM 1968. 
Fue nombrado Dr. Honoris Causa de la Universidad de Salamanca y Murcia.

\section{PUBLICACIONES}

Las publicaciones del Prof. Juan Jimenez Collado fueron muy abundantes y destacaremos unas pocas, pero sin incluir comunicaciones a congresos o reuniones ni conferencias.

Son de especial significación los 14 trabajos de investigación con su maestro, y eminente Profesor F. Orts Llorca. También con los Profesores A. Lopez Rodriguez de Cádiz y con el Prof. D. Ruano Gil de Barcelona.

"Contribución al estudio del septum intermedium en embriones humanos”. Tesis doctoral. Cádiz 1959

"La fase plexiforme del desarrollo cardiaco". Autores: F. Orts Llorca, J. Jiménez Collado y D. Ruano Gil. Ann Des. Vol. 1962.

"Contribución al conocimiento de ciertas malformaciones del intestino tenue". Autores: A. López Rodríguez; J. Jiménez Collado y J. de Dios García Garcia, UCM. Vol V. 1964.

"Estudio comparativo del volumen nuclear del Culliculus Ganglionaris de dos embriones humanos malformados, cíclope y arrinencéfalo, con uno normal de parecido estadio". Autores: F. Orts Llorca; J. Jiménez Collado Ann. Des. Vol. XIII. 1965.

"Desarrollo del paladar. Embriones de 7,5 a $25 \mathrm{~mm}$ " Autores: J. Jiménez Collado; J. Sobrado Pérez. Ann. Des. Vol XI 1966.

"Injertos heterotípicos de mesodermo segmentado de pato, anas, a pollo, gallus gallus" Autores: J. Jiménez Collado, A. Puchades Orts. Ann. Des. Vol. XVI. 1969.

"Génesis causal de los miembros". Autores: J. Jiménez Collado; J. Sobrado Pérez; P. Guillén García. Arch. Cir. Traum. Vol. 63.1978

"Developpment de l'articulation temporo-mandibulaire”. Autores: J. Jiménez Collado; A.J. Fonollá. Trab. Inst. Embr: Vol. 1.1982

"Anomalies congenitales par déficit des membres". Autores: J. Jimenez Collado; P. Guillén García. Trab. Inst. Embriol. Vol. 4.1985

"Desarrollo temprano de la glándula parótida". Autores: J. V. Sanz Casado; J. R. Mérida Velasco; J. Jiménez Collado. Trab. Inst. Embriol. Vol. 6.1987

"Aportaciones al desarrollo de la articulación temporo-mandibular". Autores: J. R. Mérida Velasco; J. F. Rodríguez Vázquez; J. Jiménez Collado. Trab. Inst. Embriol. Vol. 6.1987

"Estadios iniciales de la diferenciación pancreática en embriones humanos. Estadios 14 a 25 de O'Rahilly”.
Autories: J. Jiménez Collado; C. de la Cuadra Blanco; J. V. Sanz Casado. Trab. Inst. Embriol. Vol. 7.1990

"Nuevas perspectivas en la morfodiferenciación de la glándula submandibular en embriones humanos". Autores: R. Linares García Valdecasas; C. de la Cuadra Blanco; J. Jiménez Collado. Act. Anat. Vol. 142.1991

"The relationships between the T.M.J. disc and related muscles in hummans". Autores: J. R. Mérida Velasco; J. F. Rodríguez Vázquez; J. Jiménez Collado. Journ. Oral and max. Facial surgery. 13/3.1991

En estas más de 150 publicaciones del profesor de gran interés científico destacamos que 82 están publicadas en francés, 37 en inglés y todas extraídas de la gran hemeroteca del Instituto de embriología fundado y dirigido por él y se convirtió en el primer centro universitario de posgrado creado en la universidad española.

El Instituto de Embriología está considerado entre los tres más importantes del mundo, cuenta con una colección de embriones humanos, considerada a nivel mundial, como una de las más completas en el contexto de esta especialidad, con más de 900.000 preparaciones histológicas seriadas, clasificadas y catalogadas. Colección abierta a investigadores nacionales y extranjeros.

Los trabajos los realizó con sus colaboradores hoy catedráticos (J. Rodríguez Vázquez, R. Mérida Velasco, J. Sanz Casado, J. Sobrado Pérez, P. Guillén García, Puchades Orts, P. Martínez Ortiz y así hasta 30 profesores de universidad).

\section{ACTIVIDAD INVESTIGADORA}

\section{Tesis Doctorales}

El Prof. D. Juan Jiménez Collado ha dirigido 70 tesis doctorales en las 3 universidades-Murcia, Córdoba, Madrid- donde ejerció de catedrático de Embriología y Anatomía Humana. Todas las tesis calificadas con sobresaliente cum laude, y de ellas 8 con premio extraordinario.

\section{Tesinas}

D. Juan dirigió 23 tesinas, obteniendo, todas ellas, la calificación de sobresaliente. Siempre estuvo dispuesto a dirigir tesis y tesinas porque así se elevan los niveles de exigencia en el seno de las universidades y se distancia de la homogeneización, de la vulgaridad. En su cátedra, existía un ambiente de cooperación y familiaridad, en donde él y su mujer eran los anfitriones como en su propio domicilio.

En la cátedra de anatomía bajo la dirección del Prof. Juan Jiménez Collado, existía seriedad científica, humor del andaluz que cada verano reciclaba en su casa de Cádiz y sus procedimientos científicos los 
contrastaba con los conocimientos del mismo tipo en otros países por sus frecuentes asistencias como profesor invitado a distintas universidades con 107 comunicaciones a congresos, de ellas 66 fueron fuera de España. El tema con más frecuencia tratado fue sobre trabajos de investigación con sus maestros, con sus condiscípulos, y con discípulos y colaboradores.

$\mathrm{Su}$ actividad docente fue enorme, pero es de ley destacar no sólo el trabajo con los alumnos de pregrado, sino también a los posgraduados, para inculcarlos a ellos la vocación por la docencia.

De sus discípulos y colaboradores han logrado puestos académicos:

- 10 catedráticos entre los que se cuenta quien les habla y alguno más que nos acompaña hoy.

- 18 profesores titulares. Cuanto hemos referido nos informa de su gran trabajo docente e investigador que desarrolló a lo largo de su vida.

\section{Publicaciones}

Su nostalgia quirúrgica, por sus orígenes, lo ha ido manifestando a lo largo de sus publicaciones con 34 títulos de cursos de especialización por varios años, y de ellos, 30 tienen como base la Anatomía funcional o quirúrgica de distintas regiones del cuerpo humano, con claro predominio del Aparato locomotor y del cuello y cabeza.

Escribió o colaboró en 12 libros sobre Anatomía radiológica de distintas regiones anatómicas, otras sobre morfogénesis y desarrollo, otras sobre Anatomía y sobre bioquímica y Estomatología.

De sus libros destacamos por haber sido autor con él y con el Profesor J. Sobrado, "The Knee, La rodilla, morfogénesis, Anatomía Clínica y vías de acceso”, libro bilingüe. Editorial Mapfre 1994. Este libro exigió dos años de duro trabajo disecando rodillas de fetos y adultos para el estudio de la maduración meniscal. Libro muy consultado por los estudiosos de la rodilla y prologado por los Profesores H. Durán Sacristán y T. David Sisk (Director de Campbell Clinic. Memphis. Tennesee. USA)

\section{SU LABOR, LA DE UN GRAN DOCENTE}

Su labor universitaria se puede considerar la de un gran maestro. Puso en marcha dos Facultades de Medicina-Murcia y Córdoba- y se consolidó como gran docente en Madrid, en la UCM sustituyendo a su maestro el Prof. F. Orts LLorca.

Facultad Medicina de Murcia. Esta Facultad fue creada en septiembre de 1969/1970 sin profesores de Medicina y sin aulas donde dar las clases. Fue un curso "común" de Ciencias (Matemáticas, Química, Física, Biología e Idiomas). El primer Profesor de la Facultad de Medicina fue D. Juan Jiménez Collado que había obtenido su cátedra por oposición: fue nombrado Secretario Académico de la Facultad de Medicina y como el Decano -Prof. F. Gomar- residía en Valencia le correspondió la mayor parte de las gestiones para desarrollar la implantación de la Facultad de Medicina en Murcia, que no tenía en ese momento ni siquiera edificio propio para su ubicación.

Su labor fue fundamental para la consolidación y el desarrollo de la Facultad de Medicina de Murcia. Gestiones con las autoridades provinciales y locales, con la delegación de Sanidad, Colegio de Médicos, etc..., que fueron abriendo camino para conseguir la ampliación del número de aulas, de instalaciones administrativas, de espacio para la ubicación de las Cátedras, etc...

En cuanto a su labor docente, inició él sólo la enseñanza de sus asignaturas (Anatomía 1 y 2, Neuroanatomía, Embriología Humana y Anatomía Radiológica). Pronto se le unió un joven profesor interino, el Dr. Alfonso Puchades Orts, hoy Catedrático en la Facultad de Medicina de Alicante (Universidad Miguel Hernández).

También se rodeó de profesores contratados o interinos seleccionados entre profesionales prestigiosos de Murcia que constituyeron los principales puntales entre los profesores que iniciaron esta Facultad.

En el año 1975 terminó la primera promoción de Medicina de Murcia.

Es de destacar su implicación en la incentivación y formación de nuevos profesores, inculcando su devoción por la Universidad, tanto en el aspecto docente como investigador, dirigiendo numerosas tesis doctorales y preparando profesores en formación para que consiguieran superar oposiciones y consolidarse en la Universidad. Esto eleva su rango a la categoría de MAESTRO.

Durante su estancia en Murcia realiza un brillante trabajo docente dirigiendo varias tesis doctorales y dos discípulos lograron la plaza de Prof. Titular de Anatomía Humana (M. Nombela Gómez y P. Martínez Ortiz).

En 1970-1976 en Murcia D. Juan vivió en un hotel Rincón de Pepe- y esto fue considerado como signo de provisionalidad.

Aquí aprendió a amar la cocina murciana y degustó y se enamoró de la hueva y mojama con almendras fritas con sal y también las verduras a la plancha.

Después 1976-1977 en Córdoba también vivió en un hotel -abundando más en la provisionalidad-y en 1977 a Madrid y ya vivió en su piso. Todos sus pasos docentes hasta llegar -o volver- a Madrid los tenía cuidadosamente planificados y que deberían ser en la plenitud de su edad, elegante, fogosos y envidiable energía. En su obra docente se ven rasgos que nos descubren al matemático por el rigor exigente, organización sistemática y precavido en aceptar ideas sugestivas o brillantes pero difíciles de demostrar. 
Nada nuevo, muchos de los profesores de la Academia vivieron estas vicisitudes hasta lograr la cátedra en la Universidad Central.

Facultad de Medicina de Córdoba. En el año 1975 fue nombrado en virtud de concurso-traslado Catedrático de Anatomía y Embriología Humana de la Facultad de Medicina de Córdoba, también Decano y Director del Hospital Clínico. Se llevó a Córdoba su gran experiencia adquirida en Murcia y a su primer alumno interno como profesor contratado D. Pascual Martínez Ortiz, hoy Catedrático de Murcia. Repitió su enorme trabajo de Murcia y puso en marcha otra Facultad de Medicina.

Facultad de Medicina de Madrid, UCM. Tras consolidar la Facultad de Medicina en Córdoba el año 1977 obtuvo en virtud de concurso-traslado la Cátedra de Anatomía Humana de la UCM que había dejado vacante su maestro el Prof. D. F. Orts LLorca y que dirigió hasta su jubilación en el año 2002, y cinco años más de Prof. Emérito (cuarenta y nueve años de actividad docente. Casi medio siglo)

No se puede terminar este muy escueto resumen del Prof. Juan Jiménez Collado sin destacar sus excelentes cualidades docentes, haciendo fácil la comprensión de materias complejas como son la Embriología y la Anatomía Humana. Su dominio de la pedagogía y su gran habilidad para el dibujo en la pizarra con las tizas de colores hacía que las asignaturas pareciesen fáciles.

Con ocasión de recibir una distinción veinte años después de haber salido de Murcia, comentó:

"Murcia para mí ha sido y es un retablo de colores, donde el siempre azul de su cielo, se viste con el ocre de su sierra, el cálido verde-esmeralda de sus frutales, el siena tostado de sus pueblos, el blanco de sus almendros en flor y el rojo pasión de una tierra fértil, recia y agradecida, mosaico y obra incomparable, alfombra y vergel, por donde discurre solemne el Segura, lento como un patriarca cansado de fecundar, padre de bancales henchidos y sultán de la huerta."

Además añadió, "aprendí como el mayor acierto del Maestro, a mi modesto juicio, es conseguir que sus discípulos por él formados, hayan sabido conciliar su criterio, saber y responsabilidad científica y humana, conservando siempre su propia personalidad."

También señaló "los maestros, pienso, son como los padres, que pueden dar a sus hijos todo su amor, pero no sus pensamientos; pueden abrigar sus cuerpos, pero no sus almas."

"Esto es lo que aprendí y me enseñaron mis alumnos durante los siete años que en Murcia permanecí. Al marcharme de Murcia en 1975, conmigo vinieron siete alumnos, hoy todos ellos Doctores y acreditados profesionales y docentes; formamos y bien lo saben, una familia plena de responsabilidades, trabajo y compromisos." Así acabó su conferencia muy aplaudida.

\section{EN LA ACADEMIA DE MEDICINA}

Comentaba D. Juan, que él se acercaba frecuentemente a la Academia Nacional de Medicina acompañando a su maestro el Prof. F. Orts LLorca, Miembro Numerario de la Academia.

Ya tenía experiencia en Academias de Medicina pues era miembro correspondiente de la Real Academia de Medicina de Cádiz (1966), Miembro Numerario de la Real Academia de Medicina de Murcia (1973), cuando fue nombrado Miembro de Número de la Real Academia Nacional de Medicina de España (1993) ocupando el sillón 49, de "Biología del desarrollo y Genética". Lee su discurso de ingreso el 1 de junio de 1993 sobre "Determinación y Diferenciación Cardiaca" y la contestación la hizo el Prof. D. Hipólito Durán Sacristán. También desempeñó con gran brillantez el cargo de Secretario General de la RANME de 1999 a 2008.

En el año 2000 fue nombrado Académico de Honor de la Real Academia de Medicina de Cantabria.

\section{DISCURSO DE INGRESO}

En este trabajo de ingreso en la RANME, "Determinación y Diferenciación Cardiaca", D. Juan, el Académico que se nos ha ido es, "autor, guionista y actor”, como señaló el Prof. H. Durán Sacristán en su discurso de contestación. Sobre este tema publicó cuatro trabajos con el Prof. Orts LLorca, que fueron los primeros estudios de la literatura mundial sobre rotaciones de áreas presuntivas e injertos marcados con isótopos radiactivos.

Otros diez trabajos más publicó con sus colaboradores sobre corazón.

En este estudio comenzó analizando los "orígenes del mesodermo cardioformador" su localización, límites de las áreas prospectivas, así como su ordenamiento y organización en las fases iniciales organodependientes.

En la segunda parte estudia "los movimientos del mesodermo precardiaco" de los cuales tanto puede ser responsable un proceso de diferenciación espontánea o dependiente de una inducción.

El estudio es practicado en anfibios y en aves, con la colaboración de los Profesores J. Sobrado Pérez, A. Puchades Orts y P. Guillén García.

En el capítulo siguiente se refiere a la "microanatomía y propiedades estructurales" aludiendo que las regiones con potencia prospectiva cardiaca presentan una especificidad morfológica y metabólica en sus potenciales de acción y con el último capítulo estudia las "propiedades funcionales y dinámicas" de las distintas poblaciones celulares. Es el trabajo de una escuela prestigiosa. 


\section{PRIMEROS LATIDOS DE LA VIDA}

El segundo y gran trabajo de investigación lo presentó en la Sesión Inaugural del Curso Académico 2011 de nuestra Academia que constituyó uno de los actos más relevantes y emotivos que protagonizó el Prof. J. Jiménez Collado en defensa de la vida, tuvo lugar en esta misma sala (18 de enero de 2011) el discurso que pronunció lo tituló: "Biología del desarrollo e identidad del embrión humano"

Esta sala en la que nos encontramos, llena de autoridades académicas y políticas, una vez acabado su largo, emotivo y muy científico discurso, puesto en pie mostró con una muy larga ovación su conformidad a la defensa de la vida y a sus muy sólidos argumentos científicos desarrollados por el conferenciante para justificar su tesis.

El proceso de autocreación que denominamos Desarrollo Embrionario, ha de ser interpretado como la transcripción del mensaje inscrito en los cromosomas del gameto cuya realización es el paso de potencia a acto en el devenir autoformativo propio de los seres vivos. Esta dialéctica entre potencia y acto, entre promesa y realidad, es en el fondo el marco de la síntesis temporal de la vida, y aún más en su inicio.

Actitud valiente por exponer sus ideas sobre el origen de la vida de forma tan contundente, con fuerza, pasión y con referencias a la Iglesia Católica, pero eso sí, apoyadas en amplísimos conocimientos sobre embriología humana en el campo experimental.

La Embriología ha contribuido entre otros hechos de la Ciencia Médica con la formulación de numerosas ideas sobre las cuales se forma nuestro concepto de materia viviente. Hoy sabemos cómo las células reproductoras aportan tan excelente material que las leyes fundamentales de desarrollo pueden deducirse rápidamente del conjunto de información que nos dan.

De hecho, los dos elementos en la reproducción sexual representan el fundamento, síntesis y origen de un nuevo ciclo vital.

La Embriología, a través de los siglos ha elaborado un frondoso conjunto de conocimientos que evidencia la insaciable curiosidad humana respecto a sus orígenes "Quien vea las cosas desde su comienzo tendrá de ellas la mejor y más perfecta imagen" aseveraba ya Aristóteles que fue el primer autor de un tratado de Embriología, cuya amplia visión de la naturaleza viviente se adelantó mucho a su época.

No obstante, el criterio morfológico continuó siendo fundamental pues la Embriología es eminentemente una ciencia de la forma o quizá mejor de la génesis y transformación dinámica de la forma.

Nace así la Embriología Experimental, donde el investigador deja de ser un mero observador para intercalarse en el proceso cuya causa trata de averiguar.
Se puede decir que el avance en la Ciencia y en la Embriología, especialmente, se realiza de una manera discontinua, por brotes.

En la segunda mitad del pasado siglo hemos asistido a un mayor y mejor conocimiento del origen de la vida; sin embargo, no hay que olvidar que la fecundación o singamia fue observada por primera vez por Hermann y Hertwing en 1875.

Una vez producida la fusión y singamia, se inicia una cascada de procesos que codifican el normodesarrollo, procesos a los que hemos contribuido a su estudio y génesis formal: así aparece la fase de totipotencialidad, blastocística, preimplantación, hojas germinales, polaridad, línea primitiva... todos y cada uno de estos procesos integrados, orientados y coordinados en una única determinación morfogenética.

El periodo organogénico embrionario finaliza a los 60 días, cuando el embrión tiene $30 \mathrm{~mm}$; a partir de este momento se inicia el periodo fetal, periodo en el que todas las estructuras y órganos están claramente definidos.

Nada mejor que dos preguntas: ¿desde cuándo, desde qué momento se ha de aceptar científicamente que el embrión tiene vida? Y la segunda: jes el embrión humano una persona, un ser humano? Y si es así, ¿existen criterios o mecanismos biológicos que puedan determinarlo?

Este embrión humano ha adquirido y es poseedor de estructuras, formaciones y caracteres del ser humano, procesos que no eliminan la fase anterior sino que la integra y desarrolla de modo armónico y controlado en un determinismo orientado hacia una finalidad proyectada.

Ha sido establecido y es por todos científicamente aceptado que nada es anterior al embrión; en el estadío que precede al embrión solo hay un espermatozoide y un ovocito; sabemos y ya lo hemos comentado que solo en la fecundación, estas células se transforman en un cigoto que es un embrión unicelular, estamos pues ante el embrión de una sola célula que se desarrollará iniciando un camino único e irreversible del que emergen formas, estructuras, sistemas... tanto morfológicas como moleculares nuevos antes inexistentes.

Si la ausencia del latido cardiaco está conjuntamente con otros datos y parámetros, aceptado como signo de muerte aunque hoy prime el electroencefalograma plano, es evidente que la existencia del latido cardiaco con regularidad y frecuencia rítmica, ha de ser, es, considerada como signo de vida o si se quiere manifestación de vida.

A partir de embriones humanos de 2,3 mm 20-22 días, hemos descrito la presencia de un corazón funcional cavitado, contráctil.

Cuando aún no tenemos ni brazos, ni piernas, ni riñón, ni retina, ni oído, ni grandes articulaciones: cadera, columna vertebral... dio el primer latido 
nuestro corazón. ¿Qué hemos de decir? Personalmente considero que este nuevo ser de apenas 2 mm y 20-22 días de edad verdadera del nuevo ser, ha manifestado con la "voz de su latir" un propio e inequívoco signo de "referencia legal de vida"; ese minúsculo ser es la expresión inequívoca de una vida humana.

Eso significa que la vida del ser humano antes de que haya alcanzado los 90 días, no se encuentra protegida por la ley; representaría la abdicación de la ley penal de la protección de determinados seres humanos. Seguirían protegidos aquellos que pueden defenderse por sí mismos, aquellos que han podido alcanzar la vida independientemente, aquellos que han tenido la suerte de estar más tiempo en contacto con la madre. Es la primera vez quizá en nuestra Historia que ocurre algo semejante; supondría el reconocimiento del derecho a eliminar, a destruir, a matar a un ser humano distinto de la madre y titular del derecho a la vida.

La Dra. Anne Mac Laren, embrióloga, defendió el término de "preembrión", periodo de indeterminación biológica del embrión durante sus primeros 14 días e indicar que es una realidad distinta a un ser humano con vida.

El Prof. J. Jiménez Collado refiere en su discurso que la definición de "preembrión" que se quiere usar en base a "determinados postulados e interés nunca orto-biológicos" no es más que una ficción legal, un artificio lingüístico que no tiene fundamento científico ni ético en cuanto es utilizado para destruir una vida naciente.

La libertad de la Ciencia y la Investigación Científica definida como valor fundamental de nuestra Sociedad, debe compaginarse con la responsabilidad, respeto y deber dado por la naturaleza a vivir en cualquier estadío de su desarrollo biológico.

La vida humana es el supuesto ontológico sin el que los restantes derechos no tendrían existencia posible, dice nuestra Constitución.

\section{SINGULARIDADES POCO CONOCIDAS DEL PROF. JUAN JIMENEZ COLLADO}

Nos vamos a referir a tres detalles o aspectos de su vida docente de profesor de Anatomía y Embriología Humana, no muy conocidos o al menos poco comentados, por la importancia que tuvieron en su devenir profesional. Los tres se superponen, y tuvieron su origen en la influencia que tuvieron desde el principio los Profesores F. Orts Llorca y Antonio López Rodriguez del que comentaba que fue su primer maestro, con sus enseñanzas sobre embriología y sus técnicas (1959)

Acerca del primer detalle a destacar es que sus estudios se van centrando en trabajos sobre intervenciones -micro-intervenciones- en embriones de pollo de la raza Leghorn Cornish en estudios entre
8 y 9 somitos. Con ello trataba de esclarecer los términos y propiedades de regulación y regeneración cuando los esbozos de órganos primitivos ya están constituidos, como era el sistema neural o placa neural. Como fruto de este trabajo experimental va obteniendo excelentes hallazgos y con resultados que primero confirman sus maestros y compañeros como F. Orts Llorca, Genis Galvez y D. Ruano Gil y después reconfirmado por el Prof. TuchmannDuplessis (Cátedra Embriología-París) y H. Galera (Laboratorio de embriología-Ginebra). Esta enorme labor la inicia en Madrid, siendo Profesor adjunto de Embriología y Anatomía Humana (UCM), la continua en la Universidad de Murcia (1970-1975) y en Universidad de Córdoba (1975-1977), para desarrollarla al máximo en la UCM, cuando regresa en virtud de concurso-traslado como Catedrático de Embriología y Anatomía Humana Descriptiva y Topografía con sus técnicas (18.10.1977).

En la UCM intensifica sus trabajos experimentales en Embriología y continúa centrándose en sus iniciados estudios y enseña Embriología Humana.

Esta primera faceta como "técnico en embriología y sus técnicas de laboratorio" debe ser destacado en su haber científico y hacer diario. ¿Cuántos embriones y fetos humanos y no humanos estudio y preparó? Cientos, sí cientos.

¿Cuántas horas dedicó? Muchísimas. Cuántas veces, a horas y días no lectivos le decíamos ¿otra vez...? No sabía cómo preparar este embrión -decía- y le estaba dando vueltas a la técnica, y ... mira, fíjate que corte más espectacular ha salido.

El segundo aspecto a destacar, sería la de “Técnico en Fotografía científica y sus técnicas" Miles de microfotografías, que tiñe con el método Bielschosky, que tiene que estudiar y revisar una a una para escoger las principales, las que aportan las mejores imágenes para la investigación que estaba desarrollando. Tenía un estudio fotográfico excelente. Trabajos que realizaba totalmente sólo, trabajo ingente que requiere una enorme preparación como técnico y dotes interpretativos que sólo el domina.

Un tercer aspecto fue el logro para "conservar los cadáveres". Sintetiza una sustancia derivada del Peróxido Dialquil Cetona a la que denomina "complucal", primero y único sustitutivo regulado por el Ministerio de Sanidad y Consumo de Formoaldehido como fijador de tejido, conservador de cadáveres, sustancia biocida, sin toxicidad y riesgo sanitario-laboral con patente mundial, cediendo sus beneficios a la Universidad Complutense de Madrid.

Todo lo reseñado además compartido con sus obligaciones académicas, que progresivamente aumentan y atiende con una dedicación digna de un Titán del trabajo.

Además, publica continuamente, dirige tesis, asiste a congresos y funda y dirige el Primer Centro Universitario de Postgrado en España 1982. 


\section{JUSTIFICACIÓN FINAL}

Quiero terminar mi necrológica del Prof. Juan Jiménez Collado con algunas frases que la definen muy bien:

"La Universidad ha sido para mí, mi equilibrio, mi vocación y mi razón de ser; en ella he pasado toda mi vida".

"Han pasado cuarenta y nueve años, desde 1958, en que obtuve por oposición la plaza de Profesor de Anatomía Humana en la Facultad de Medicina de Cádiz hasta mi jubilación en 2002, y hasta 2007 como Prof. Emérito, en la Facultad de Medicina Complutense de Madrid; han sido cuarenta y nueve años de docencia universitaria ininterrumpida, aprendiendo y enseñando, intentando plantar una semilla con la esperanza de que germine, crezca y fertilice".

"Si así no lo recordara traicionaría a mis principios, responsabilidad y vida misma. Ahora a los 80 años no puedo o mejor, no quiero cambiar".

En una Audiencia del Papa Juan Pablo II el 1 de marzo de 1994 con la asistencia del Presidente, Vicepresidente, Secretario de Acta y Secretario General de nuestra Academia les comentó al finalizar "jamás puede justificarse la destrucción de un ser humano en fase inicial de su existencia: la vida humana es sagrada porque desde el primer momento es la acción creadora de Dios".

$\mathrm{Y}$ termino con su gran legado, primero en el campo de la investigación con "mayúsculas" de la embriología para desentrañar el desarrollo e identidad del embrión humano; y donde más, y en segundo lugar, su ingente labor docente en sus alumnos y profesores que gracias a sus enseñanzas lograron consolidarse en la Universidad; además y digno de destacar en tercer lugar, su dominio de la pedagogía y su gran habilidad para el dibujo en la pizarra que lograba que sus enseñanzas de la anatomía y la embriología pareciera fácil, y como final, y cuarto lugar, en el ámbito de la salud su labor se agigantó al trasmitir a sus alumnos de pregrado y postgrado los grandes conocimientos anatómicos que han supuesto las mejores alforjas en la difícil profesión de la medicina.

Sí, a D. Juan la vida se le fue, pero nos regaló el consuelo de su memoria. Creyente, católico y con gran afán quiso alcanzar la verdad y estoy seguro que hoy estará feliz en el seno de Quien es eterno Amigo y absoluta Verdad.

Señorías, que la evocación de su ejemplo de excelente maestro de la Embriología y Anatomía Humana Española, enriquezca el breve homenaje que, con tristeza, no consolada he manifestado a su memoria.

D. Juan, como otros maestros, fueron grandes en edad, en consejo y en saber. Cuando faltan estos maestros, sentimos la sensación egoísta del desamparo.
Espero que en la descripción de su trabajo docente $\mathrm{e}$ investigador por mi torpeza haya podido menoscabar la grandeza de su obra anatómica.

El bien que hacen los hombres docentes, perdura sobre su memoria.

D. Juan, fin no tendrá mi agradecimiento. He dicho.

\section{DECLARACIÓN DE TRANSPARENCIA}

El autor/a de este artículo declara no tener ningún tipo de conflicto de intereses respecto a lo expuesto en el presente trabajo.
Si desea citar nuestro artículo:

Guillén García P. Sesión necrológica en memoria del Prof. Juan Jiménez Collado. An RANM. 2021;138(01).supl01: 28-36. D0I: 10.32440/ar.2021.138.01.supl01.art07 